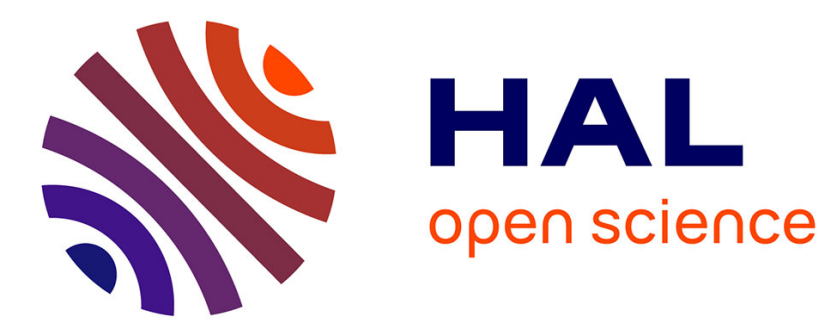

\title{
A Robust System for Visible Light Communication
} Alin Cailean, Barthélemy Cagneau, Luc Chassagne, Suat Topsu, Yasser Alayli, Mihai Dimian

\section{To cite this version:}

Alin Cailean, Barthélemy Cagneau, Luc Chassagne, Suat Topsu, Yasser Alayli, et al.. A Robust System for Visible Light Communication. 5th International Symposium on Wireless Vehicular Communications, 2013, Dresde, Germany. pp.1-5. hal-01208101

\section{HAL Id: hal-01208101 \\ https://hal.science/hal-01208101}

Submitted on 13 Oct 2015

HAL is a multi-disciplinary open access archive for the deposit and dissemination of scientific research documents, whether they are published or not. The documents may come from teaching and research institutions in France or abroad, or from public or private research centers.
L'archive ouverte pluridisciplinaire HAL, est destinée au dépôt et à la diffusion de documents scientifiques de niveau recherche, publiés ou non, émanant des établissements d'enseignement et de recherche français ou étrangers, des laboratoires publics ou privés. 


\title{
A Robust System for Visible Light Communication
}

\author{
A. Cailean ${ }^{1,2}$, B. Cagneau ${ }^{1}$, L. Chassagne ${ }^{1}$, S. Topsu ${ }^{1}$, Y. Alayli ${ }^{1}$, M. Dimian ${ }^{2}$
}

\begin{abstract}
In this paper, we present the second version of our system which is dedicated to Visible Light Communication (VLC) for automotive applications. It exhibits improved performances compared to the first version regarding the distance for which data are transmitted. It also includes real time variable gain adjustment in order to increase robustness against environmental conditions. The system is detailed and experimental results are provided.
\end{abstract}

\section{INTRODUCTION}

$\mathrm{N}$ owadays, led systems are used as a standard on commercial vehicles and road infrastructures. Led are very convenient for intensity modulation like in telecommunication fields and help to develop Visible Light Communications (VLC). In parallel, automobile industry has greatly improved vehicles safety and comfort during the last years. More and more intelligence is embedded thanks to the sensors. As a consequence, the instrumented systems can sense environmental conditions to adapt their behaviors. Intelligent Transportation Systems (ITS) is an important challenge for the next years. Cooperation between vehicles or with road infrastructures is a key point to enhance the efficiency and the safety in heavy traffic density on highways or in city traffic. It includes Vehicle to Vehicle cooperation (V2V), or Vehicle to Infrastructure (V2I or I2V) communications.

The second field of research relates to the perception of the environment which also includes communications to share information. The transmission of data between vehicles is a crucial point to communicate information concerning the state of the vehicle (brake, speed, acceleration, engine failure, etc), or traffic information (state of

\footnotetext{
${ }^{1}$ LISV laboratory of the University of Versailles Saint-Quentin, 10-12 avenue de l'Europe - France (corresponding author phone: +33 1392549 44; e-mail: barthelemy.cagneau@uvsq.fr).

2 Department of Computers, Electronics and Automations, Stefan cel Mare University, Suceava, - Romania.

This work was sustained by the competitive cluster Moveo and is partially funded by the national FUI 11 program (project CoDrive).
}

traffic-lights, accidents, traffic jams, line works, etc).

In this field, Visible Light Communications is well suited because of its ease of use, its low cost and high performances. Dedicated sensors, such as the prototype presented in this paper or in [1];[2], are a prerequisite to enhance communications between the vehicles but also with infrastructures. Several studies have been conducted for communications between vehicles and traffic light [3]-[5]. Infrared link was also used in addition to radiofrequencies for platooning [6]. Modeling of Vehicular Ad Hoc Networks (VANETs) with Intelligent Traffic Light (ITL) shows the interest of communications with traffic lights [7]. The challenge is to provide communications with high bandwidth to decrease the perception phase duration. The recent normative efforts with the IEEE 802.11p standard [8] and the IEEE 802.15.7 are a proof of this challenge in the ITS domain. 


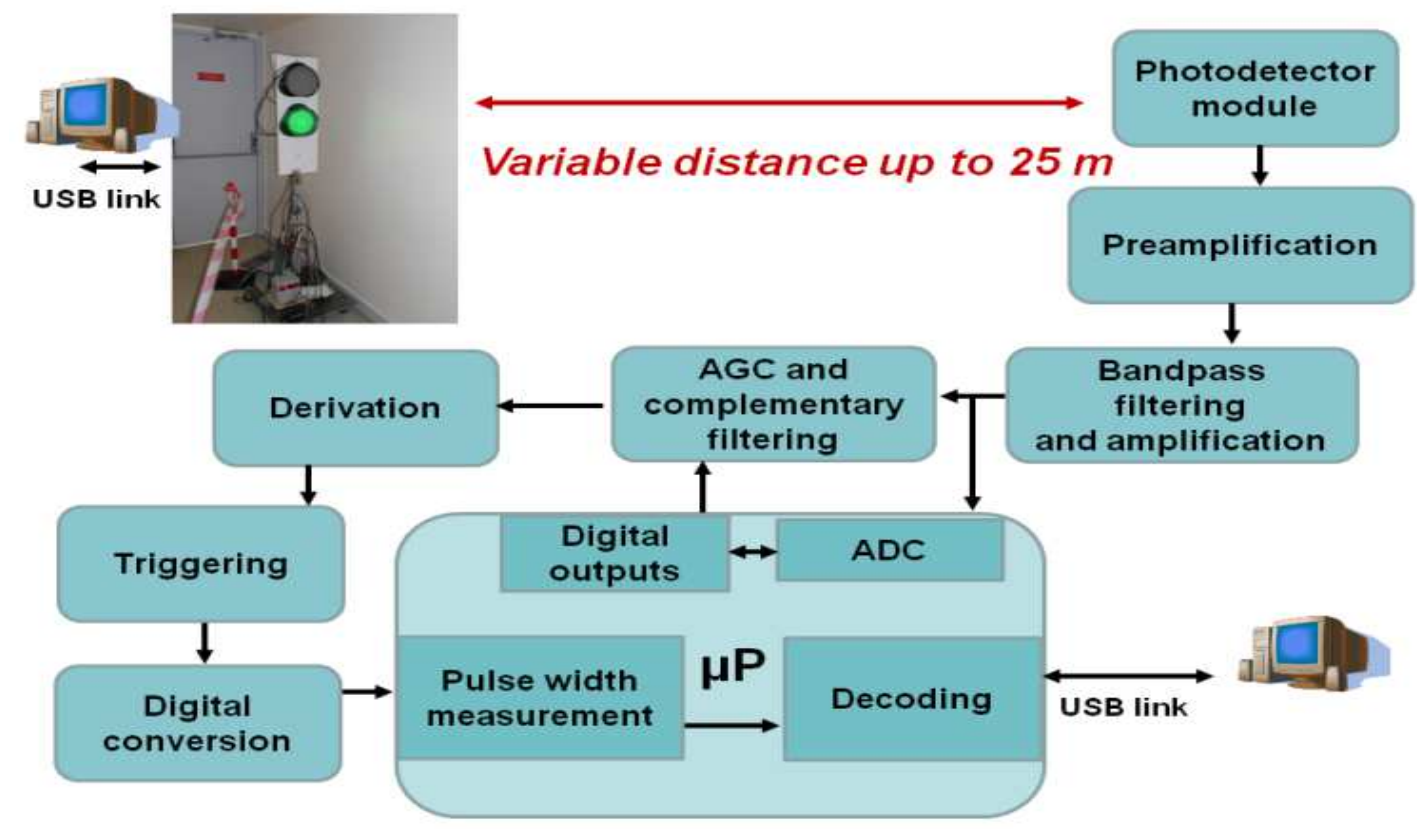

In this paper, we present a prototype to transmit data through different channels. We focus on VLC technology. A Bit Error Ratio (BER) lower than $10^{-7}$ can be considered as a very promising result as we only explored the physical layer of the communication. With an error-correcting code module, like those based on Direct Sequence Spread Spectrum (DSSS) techniques presented in [3] or on pseudo-noise codes, a final BER up to $10^{-8}$ or few $10^{-9}$ could be expected.

We deposited a patent on optoelectronics system for communication and inter-vehicle distance measurements [10]. The main application for the system presented in this paper is the communication between the traffic lights and the car in order to transmit, for example, the countdown before the next traffic light signal change. The interest is also to alert the vehicles and to control the engine.

\section{DESCRIPTION OF THE PROTOTYPE}

The synopsis of our prototype dedicated to VLC is represented in Figure 1. The aim is to communicate by using a traffic light emitter (red and green). Power modulation is used to transmit digital information. All the components have been chosen for their low cost and their compactness and are compatible with industrial prototypes.

The light is current modulated with OOK (OnOff Keying) amplitude modulation with a microcontroller and a digital power switch. A digital frame has been defined. Several synchronization bits begin the frame to alert the receiving board that a message is sent. The rest of the frame is composed of start and stop bits and an additional flag to notify the data frame length. The clock of the receiver is not synchronized with phase locked-loop for simplicity. The frequencies involved (few kilohertz) are low enough to be relatively not sensitive to frequency drifts. An electronic board handles the decoding which is made online by a microcontroller. For test purposes, the maximum data length is 96 bytes but could be longer. Details of the reception board are given in the following parts.

\section{A. Discussions about the coding}

Two codes have been implemented: the biphase (Manchester code) and the Miller code. Miller code is less popular than Manchester but it could be convenient for further MIMO applications. This is the reason why we have chosen to simulate and to evaluate it. The Power Spectral Densities (PSD) of these two codes are expressed in [13]. As stated in [15], the Miller code behavior seems to be very suitable in order to perform multi-channels communication. Its PSD is indeed centered on a short bandwidth range. This allows for efficient analog or digital filtering.

In our prototype, the microcontroller can be switched either on Manchester or Miller in order 
to test different configurations. For the detection board, the temporal properties of both codes are also important to design the electronics without using complex decoding algorithms.

\section{B. Discussion about the reception module}

A low cost silicon photodetector is coupled with a low cost pre-amplifier electronics. The aim of the system is to transmit over a distance up to 25 $\mathrm{m}$ whatever the environmental conditions. The sensitive element has been conditioned with a transimpedance circuit.

Once the signal to noise is optimized, it is preamplified even for minimal levels around tens millivolts (whatever the distance up to $50 \mathrm{~m}$ ). An analog band-pass filter suppresses the offset due to the daylight and filters high frequencies noise. The signal is then digitalized with the ADC (Analogto-Digital Converter) included in a low cost microcontroller (Microchip 18F2550) that is the core element of the signal processing.

First experimental results showed that a BER lower than $10^{-7}$ can be obtained for a pre-defined value of the gain and for a long distance. However, while the distance is decreasing, it obviously leads to the saturation of the receiving module. For this reason, depending on the level of the signal, a variable gain is processed on a complementary gain-filtering stage. An average of previous ADC values is computed so that switches can be controlled with the microcontroller to change the gain and make the system robust. This stage is defined as Automatic Gain Control (AGC) in Figure 1.

Finally, as soon as the signal is amplified, it is derived with a high-pass filter. The derivative of a square signal leads to alternated positive and negative pulses as illustrated in Figure 2. Then, the signal is triggered and the system converts the signal into two-level digital signals (light on and light off). It is then sent to the microcontroller to measure the width of the pulses with a precise clock (the microprocessor quartz crystal is an external one at $20 \mathrm{MHz}$ frequency).

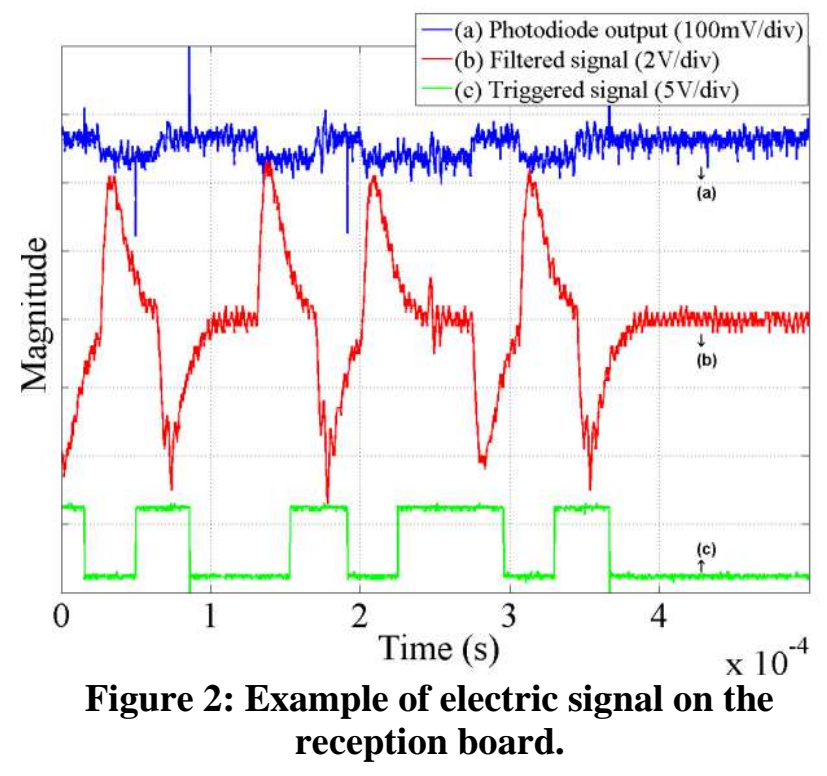

III. EXPERIMENTAL RESULTS

\section{A. Measurements}

The experimental tests have been conducted with a traffic light (red and green lights) installed in the corridor of the laboratory or outdoor.

Basically, the message transmitted during the experiments is sent to the emitter and the frame indicates if Miller or Manchester code is selected. The receiver decodes the data in real-time and an algorithm allows post-processing or calculation of errors. For first experiments, a specific message is sent continuously using a modulation frequency of $15 \mathrm{kHz}$. The accuracy and the stability of the clock of the microcontroller are good enough so that we do not need to synchronize the emitter and reception modules. The transmission of the clock is also not required and the system is thus running with asynchronous link which is easier and cheaper.

Sets of data of 10 million bits have been sent. We can consider that in any road applications, a BER lower than $10^{-7}$ is good enough. Furthermore, the calculated BER is for the direct link but could be highly improved if necessary with error detecting codes, correlation techniques, or redundancy coding frames or protocols. Tests have been realized either outdoor or inside a building in a corridor with artificial lights (neon lights that provide a strong parasitic $100 \mathrm{~Hz}$ signal added on the useful signal). Table 1 summarizes the principal results of the sets of data. 


\begin{tabular}{lll}
\hline Code & BER & Conditions \\
\hline Manchester & $<10^{-7}$ & $\begin{array}{l}50 \mathrm{~m} \text { outdoor, } \\
\text { daylight. Red light }\end{array}$ \\
Miller & $<10^{-7}$ & $\begin{array}{l}50 \mathrm{~m} \text { outdoor, daylight. } \\
\text { Red light }\end{array}$ \\
Manchester & $<10^{-7}$ & $\begin{array}{l}36 \mathrm{~m} \text { outdoor, daylight. } \\
\text { Green light }\end{array}$ \\
Miller & $<10^{-7}$ & $\begin{array}{l}36 \mathrm{~m} \text { outdoor, daylight. } \\
\text { Green light }\end{array}$ \\
Manchester & $<10^{-7}$ & $\begin{array}{l}20 \mathrm{~m} \text { inside a building } \\
\text { with neon light on Red } \\
\text { light } \\
20 \mathrm{~m} \text { inside a building } \\
\text { with neon light on Green } \\
\text { light }\end{array}$ \\
Miller & $<10^{-7}$ & \\
\hline
\end{tabular}

Table 1: Bit Error Ratio (BER) for Miller and Manchester codes at $15 \mathrm{kHz}$ modulation frequencies; green and red light have been tested in different conditions.

These results demonstrate that the prototype is well adapted for data transmission over short or medium distances up to $50 \mathrm{~m}$. Results show 0 errors for $10^{7}$ bits sent for both Manchester and Miller codes.

The indoor tests have been made in a corridor, limited to $20 \mathrm{~m}$ range because of the limited length of the building. The aim was to test the influence of neon lights located in the corridor. When the light is on, the remaining $100 \mathrm{~Hz}$ on the photodetector module is well filtered and has no influence at the $10^{-7}$ level. Some errors can appear when the light is switch on or switch off because of transient pulses that can affect the frames but it is minor drawback. Both red and green lights have same performances.

The outdoor tests have been made in different sun expositions, up to $50 \mathrm{~m}$ distance. The green light shows lower performances and the associated maximum distance is around $36 \mathrm{~m}$. Firstly, it is probably due to the sensitivity of the photodetector that is lower for green wavelength than for the red one. Secondly, the sun spectrum is more

disturbing in green range than in red one. We plan to enhance this point in the future with higher gain or plastic color filtering to reduce the influence of the sun light and to improve the signal to noise ratio.

\section{B. Variable gain for robustness}

In this subsection, we present the results for a frequency of $15 \mathrm{kHz}$. The results are similar for both Manchester and Miller codes.

As explained in previous section, the system allows for Automatic Gain Control (AGC) in order to receive data for both short and long distance. AGC is especially useful at short distance because of the saturation of the photodetector module.

For this experiment, we just compute the gain value in real time to adapt the switches on the board. To illustrate how this value is affected, we present the results in Table 2 for some distances.

\begin{tabular}{llllllll}
\hline $\begin{array}{l}\text { Distance } \\
\text { (m) }\end{array}$ & $\mathbf{1}$ & $\mathbf{4}$ & $\mathbf{5}$ & $\mathbf{6 . 5}$ & $\mathbf{8}$ & $\mathbf{1 1}$ & $\begin{array}{l}\mathbf{1 6}- \\
\mathbf{2 0}\end{array}$ \\
\hline $\begin{array}{l}\text { Gain } \\
\text { value }\end{array}$ & 1 & 1.3 & 2.5 & 3 & 4 & 6 & 8 \\
(AU) & & & & & & & \\
BER & & & \multicolumn{5}{c}{$<10^{-7}$} \\
\hline
\end{tabular}

Table 2: Gain value with respect to the distance when AGC is performed.

Table 2 clearly shows that the gain of this stage is amplified with a factor 8 between the shortest and the longest distance (10 discrete values are possible for the gain). Without such variable gains, the BER was pretty high for short distances making the system unsuitable when the car is too close to the traffic light. Here, when AGC is performed, we were able to transmit data with zero error for 10 millions of bits sent.

\section{Multi-channel capabilities}

First results concerning the multi-channel capabilities of the prototype are presented hereafter. The results which are provided have been obtained for several distances up to 15 meters.

During the experiment, we used the Milled code (results are similar for Manchester code). The frequency of the emitter part was switched between 6 and $15 \mathrm{kHz}$ allowing for two different channels of communication as explained in [15]. The switch occurs every 61600 bits for a given distance (1100 message composed of 7 ASCII 
characters of 8 bits). The table 3 summarizes the results that we obtained while sending 10 millions of bits.

\begin{tabular}{lcc}
\hline $\begin{array}{c}\text { Distance } \\
(\mathbf{m})\end{array}$ & $\begin{array}{c}\text { Incorrect } \\
\text { Bits }\end{array}$ & Invalidated frames \\
\hline $\mathbf{2}$ & 0 & 252 \\
$\mathbf{5}$ & 45 & 255 \\
$\mathbf{1 0}$ & 225 & 307 \\
$\mathbf{1 5}$ & 350 & 319 \\
\hline
\end{tabular}

\section{Table 3: Frequency switching for multi-channels purposes.}

It can be seen that errors occur when the frequency is switched when transmitting data. This is due to the fact that the frequency update is lower for the receiver than for the emitter. Therefore, it begins to decode actual messages with previous frequency values. This necessarily implies errors while receiving data. The invalidated frames correspond to the ones that contain false positive or negative edges. To detect such kind of frames, it is only needed to measure the length of the edges and to compare them to the ones of Manchester or Miller codes.

While looking at these results, it is obvious that error-correcting codes must be included in future prototypes. However, these results are quite promising regarding the BER.

\section{CONCLUSION}

We have developed a prototype using commercial traffic lights and homemade emitter and receiver boards using very simple codes for visible light communications between vehicle and infrastructures. We focused on hardware electronics part and measurements of BER have been presented, both indoor with light network perturbations and outdoor with sunny conditions. The BER results are lower than $10^{-7}$ up to $50 \mathrm{~m}$. This result is good, knowing that we did not use error-correcting codes.
Next step consists in finalizing the embedded application for experiments in several road configurations with either static or moving vehicles. The optical part is made in cooperation with Valeo industry and is also dedicated to be multi-functions. It is also developed to be a vehicle inter-distance sensor. We finally want to test the system for different sunlight configurations to evaluate the influence of rising sun for example [14].

\section{REFERENCES}

[1] T. Komine and M. Nakagawa. Fundamental Analysis for Visible-Light Communication System using LED Lights, IEEE Transactions on Consumer Electronics, Vol. 50, No. 1, 100-107, 2004.

[2] H. Sing Liu and G. Pang. Positioning Beacon System Using Digital Camera and LEDs, IEEE Transactions on Vehicular Technology, vol. 52, no. 2, 406-419, 2003.

[3] N. Kumar, N. Lourenço, D. Terra, L.N. Alves, R.L. Aguiar, Visible Light Communications in Intelligent Transportation Systems, IEEE Intelligent Vehicules Symposium 2012, 748-753.

[4] M. Akanegawa, Y. Tanaka and M. Nakagawa. Basic Study on Traffic Information System Using LED Traffic Lights, IEEE Transactions on Intelligent Transportation Systems, vol. 2, no. 4, 197-203, 2001.

[5] T. Saito, S. haruyama and M. Nakagawa, A new tracking method using image sensor and photo diode for visible light raod-to-vehicle communication, $10^{\text {th }}$ International Conference on Advanced Communication Technology, Vol 1, pp 673-678 (2008).

[6] P. Fernandes, U. Nunes, Platooning with DSCR-based IVC-Enabled Autonomous Vehicles: Adding Infrared Communications for IVC Reliability Improvement, IEEE Intelligent Vehicules Symposium 2012, 517-522.

[7] C. Tripp Barba, M.A. Mateos, P. Reganas Soto, A. M. Mezher, M. Aguilar Igartua, Smart City for VANETs using warning messages, Traffic statistics and intelligent traffic light, EEE Intelligent Vehicules Symposium 2012, 902-907.

[8] IEEE, "IEEE Std 802.11p, Amendment 6: Wireless Access in Vehicular Environements", ed: IEEE, July 2010.

[9] S.G. Wilson, M. Brandt-Pearce, Q. Cao, J. Leveque, Free space optical MIMO Transmission with Q-ary PPM, IEEE Transactions on Communications 53(1):204 (2005).

[10] Y. Alayli, S. Topsu, L. Chassagne, J.M. Blosseville, Patent n ${ }^{\circ} 09$ 58694, Communications par phares, 2009.

[11] T. Nagura, T. Yamazato, M. Katayam, T. Yendo, T. Fujii, H. Okada, "Improved decoding methods of visible lights communication system for ITS using led array and high speed camera", Vehicular technology conference, VTC 2010 IEEE 71 ${ }^{\text {st }}$, ISSN: 1550-2252,2010.

[12] S. Okada, T. Yendo, T. Yamazato, T. Fujii, M. Tanimoto, Y. Kimura, "On-vehicle receiver for distant visible light road-to-vehicle communication", Intelligent Vehicle Symposium, IEEE ISSN: 19310587, 2009.

[13] The mobile communications handbook, $2^{\text {nd }}$ edition, CRC Press LCC, 1999.

[14] C. Liu, B. Sadeghi, E.W. knightly, "Enabling vehicular visible light communication (V2LC) networks", Vanet'11, Las vegas, USA, 2011.

[15] A. Cailean, B. Cagneau, L. Chassagne, S. Topsu, Y. Alayli, J-M. Blosseville, Visible light communications: application to cooperation between vehicles and road infrastructures, proceedings of IEEE Intelligent Vehicle Symposium, 2012, 1055-1059. 